Article

\title{
The BMP Receptor 2 in Pulmonary Arterial Hypertension: When and Where the Animal Model Matches the Patient
}

\author{
Chris Happé ${ }^{1,+}$, Kondababu Kurakula ${ }^{2,+}$, Xiao-Qing Sun ${ }^{1}{ }^{[0}$, \\ Denielli da Silva Goncalves Bos ${ }^{1} \mathbb{D}$, Nina Rol ${ }^{1}$, Christophe Guignabert ${ }^{3,4} \mathbb{D}$, Ly Tu $^{3,4} \mathbb{D}^{\mathbb{D}}$, \\ Ingrid Schalij ${ }^{1}$, Karien C. Wiesmeijer ${ }^{2}$, Olga Tura-Ceide ${ }^{5,6,7}$, Anton Vonk Noordegraaf ${ }^{1}$, \\ Frances S. de Man ${ }^{1}$, Harm Jan Bogaard ${ }^{1}\left(\mathbb{D}\right.$ and Marie-José Goumans ${ }^{2, * \mathbb{D}}$ \\ 1 Amsterdam UMC, Vrije Universiteit Amsterdam, Department of Pulmonology, Amsterdam Cardiovascular \\ Sciences, 1081 HV Amsterdam, The Netherlands; c.happe@amsterdamumc.nl (C.H.); \\ x.sun@amsterdamumc.nl (X.-Q.S.); dsgbos@gmail.com (D.d.S.G.B.); n.rol@amsterdamumc.nl (N.R.); \\ i.schalij@amsterdamumc.nl (I.S.); a.vonk@amsterdamumc.nl (A.V.N.); \\ fs.deman@amsterdamumc.nl (F.S.d.M.); hj.bogaard@amsterdamumc.nl (H.J.B.) \\ 2 Laboratory for Cardiovascular Cell Biology, Department of Cell and Chemical Biology, \\ Leiden University Medical Center, 2300 RC Leiden, The Netherlands; k.b.kurakula@lumc.nl (K.K.); \\ C.C.Wiesmeijer@lumc.nl (K.C.W.) \\ 3 INSERM UMR_S 999, Hôpital Marie Lannelongue, 92350 Le Plessis-Robinson, France; \\ christophe.guignabert@inserm.fr (C.G.); lyieng@gmail.com (L.T.) \\ 4 Université Paris-Saclay, School of Medicine, 94270 Le Kremlin-Bicêtre, France \\ 5 Department of Pulmonary Medicine, Hospital Clínic-Institut d'Investigacions Biomèdiques August Pi I \\ Sunyer (IDIBAPS), University of Barcelona, 08036 Barcelona, Spain; TURA@clinic.cat \\ 6 Biomedical Research Networking center on Respiratory diseases (CIBERES), 28029 Madrid, Spain \\ 7 Department of Pulmonary Medicine, Dr. Josep Trueta University Hospital de Girona, Santa Caterina \\ Hospital de Salt and the Girona Biomedical Research Institut (IDIBGI), 17190 Girona, Catalonia, Spain \\ * Correspondence: M.J.T.H.Goumans@lumc.nl; Tel.: +31-715-269-277; Fax: +31-715-268-270 \\ + Both authors contributed equally.
}

Received: 13 April 2020; Accepted: 5 June 2020; Published: 8 June 2020

check for updates

\begin{abstract}
Background: Mutations in bone morphogenetic protein receptor type II (BMPR2) are leading to the development of hereditary pulmonary arterial hypertension (PAH). In non-hereditary forms of PAH, perturbations in the transforming growth factor- $\beta$ (TGF- $\beta$ )/BMP-axis are believed to cause deficient BMPR2 signaling by changes in receptor expression, the activity of the receptor and/or downstream signaling. To date, BMPR2 expression and its activity in the lungs of patients with non-hereditary $\mathrm{PAH}$ is poorly characterized. In recent decades, different animal models have been used to understand the role of BMPR2 signaling in PAH pathophysiology. Specifically, the monocrotaline (MCT) and Sugen-Hypoxia ( $\mathrm{SuHx}$ ) models are extensively used in interventional studies to examine if restoring BMPR2 signaling results in PAH disease reversal. While PAH is assumed to develop in patients over months or years, pulmonary hypertension in experimental animal models develops in days or weeks. It is therefore likely that modifications in BMP and TGF- $\beta$ signaling in these models do not fully recapitulate those in patients. In order to determine the translational potential of the MCT and SuHx models, we analyzed the BMPR2 expression and activity in the lungs of rats with experimentally induced PAH and compared this to the BMPR2 expression and activity in the lungs of PAH patients. Methods: the BMPR2 expression was analyzed by Western blot analysis and immunofluorescence (IF) microscopy to determine the quantity and localization of the receptor in the lung tissue from normal control subjects and patients with hereditary or idiopathic $\mathrm{PAH}$, as well as in the lungs of control rats and rats with MCT or SuHx-induced PAH. The activation of the BMP pathway was analyzed by determining the level and localization of phosphorylated Smad1/5/8 (pSmad 1/5/8), a downstream mediator of canonical BMPR2 signaling. Results: While
\end{abstract}


BMPR2 and pSmad 1/5/8 expression levels were unaltered in whole lung lysates/homogenates from patients with hereditary and idiopathic PAH, IF analysis showed that BMPR2 and pSmad 1/5/8 levels were markedly decreased in the pulmonary vessels of both PAH patient groups. Whole lung BMPR2 expression was variable in the two PAH rat models, while in both experimental models the expression of BMPR2 in the lung vasculature was increased. However, in the human PAH lungs, the expression of pSmad $1 / 5 / 8$ was downregulated in the lung vasculature of both experimental models. Conclusion: BMPR2 receptor expression and downstream signaling is reduced in the lung vasculature of patients with idiopathic and hereditary $\mathrm{PAH}$, which cannot be appreciated when using human whole lung lysates. Despite increased BMPR2 expression in the lung vasculature, the MCT and SuHx rat models did develop PAH and impaired downstream BMPR2-Smad signaling similar to our findings in the human lung.

Keywords: pulmonary arterial hypertension; BMPR2; BMP and TGF- $\beta$ signaling; animal models of pulmonary hypertension

\section{Introduction}

Mutations in the BMPR2 gene were the first genetic perturbations implicated in the pathophysiology of pulmonary arterial hypertension (PAH) and are still responsible for most cases of hereditary PAH (hPAH) to date [1-3]. PAH patients with a BMPR2 mutation present at a younger age with a more severe phenotype and an increased risk of death [4]. Aside from mutations in the BMPR2 gene, other genes related to BMPR2 signaling such as ALK1, CAV1, ENG, SMAD4, SMAD8, SMAD9, $B M P R 1$ and BMP9 are implicated in hPAH, albeit less frequently [5-10]. Furthermore, aberrant BMPR2 signaling has been described in non-hereditary subtypes of PAH, although descriptions of defective BMPR2 expression in human tissue remain relatively scarce [11]. Reduced or absent BMPR2 expression was observed in the lung vasculature of patients with idiopathic PAH (iPAH, then called primary pulmonary hypertension) and hPAH. Decreased levels of BMPR2 were also observed in blood-outgrowth endothelial cells (BOECs) from hPAH and iPAH patients [12,13]. Levels of phosphorylated Smad 1/5/8 (pSmad) were altered in pulmonary artery endothelial cells (PAEC) of iPAH patients compared to controls, indicative of altered BMP signaling [14]. Dewachter et al. showed a lower mRNA expression of BMPR2 in whole lung lysates from hPAH. In both hPAH and iPAH, BMPR2 mRNA expression was lower in isolated pulmonary artery smooth muscle cells (PASMCs). The reduced BMPR2 mRNA expression was not observed in isolated PAEC from IPAH and hPAH patients. In the same study, reduced BMPR2 protein (molecular weight $75 \mathrm{kDa}$ ) was observed in whole lung lysates of patients with hPAH but not iPAH patients [11]. Together, these findings put aberrant BMPR2 signaling at the center of the pathobiology of many if not most forms of PAH. However, the number of studies assessing BMPR2 expression in the PAH lung remains limited and the methodology used to study BMPR2 expression varied among studies.

It is currently hypothesized that a decrease in BMPR2 signaling leads to a disturbance in the TGF- $\beta /$ BMP balance favoring the activation of the TGF- $\beta$ signaling pathway [15]. Increased TGF- $\beta$ signaling can result in pro-proliferative and anti-apoptotic responses in PAECs and PASMCs, and increased inflammatory cytokine and chemokine production [16-19]. Although the BMP receptors typically phosphorylate Smad1/5/8 and TGF $\beta$ receptors Smad2/3, depending on the cell type and the genetic disorder, TGF $\beta$ can induce pSmad 1/5/8, albeit with a different affinity and kinetics when compared to BMP ligands. [20-22] Restoring BMPR2 signaling is therefore of interest from a treatment perspective, to stop the progression of the disease. Although, in several translational studies, drugs were tested that were hypothesized to restore the TGF- $\beta / \mathrm{BMP}$ balance and reverse experimentally induced pulmonary hypertension $(\mathrm{PH})$, basic characterization of BMPR2 expression and activity in the most commonly used PH animal models is currently still very limited [23-25]. The two most 
used animal models for PAH preclinical research are the monocrotaline (MCT) and sugen-hypoxia (SuHx) rat models. MCT is an alkaloid derived from the seeds of Crotalaria spectabilis. Once injected, MCT is metabolized in the liver into its active form and induces PAEC damage followed by the induction of pulmonary hypertension [26]. The SuHx model depends on a single injection of the vascular endothelial growth factor receptor inhibitor sugen to induce PAEC damage combined with a 4 -week hypoxic (10\% of oxygen) stimulus [27]. Because both the MCT and SuHx rat models rely on chemically and hypoxia-induced hits for the subsequent development of $\mathrm{PAH}$, in the following weeks rather than decades, it is likely that the BMP signaling pathway in experimentally induced PAH acts differently than observed in the human disease, and might even vary between models. Since in translational research, using the most representative animal model to test new compounds is crucially important, the aim of this study was to describe BMPR2 receptor expression and downstream signaling in the MCT and SuHx rat model for experimentally induced PAH and to compare these findings to altered BMPR2 signaling in the lungs of $\mathrm{PAH}$ and hPAH patients. Additionally, we will compare the expression levels in whole lung lysates, as determined by Western blot, vs. vascular expression only.

\section{Materials and Methods}

\subsection{Patient Tissue Samples and Animal Experiments}

Human lung tissue samples were obtained from hPAH $(n=7)$ and iPAH $(n=7)$ patients upon autopsy. Control lung tissue samples $(n=8)$ were obtained from patients who had died from non-pulmonary causes (cancer, suicide) as previously reported [28]. The usage of samples was approved by the Institutional Review Board of the VU University Medical Center (Approval number: VUMC BUP 2013-5B) and Comite de 'Protection des Personnes (CPP) Ile-de-France VII, Paris (Approval number: 2018-A01252-53). All the samples were formalin fixed and paraffin embedded according to common tissue-processing protocols. Animal experiments were approved by the animal welfare committee of the VU university and were conducted in accordance with the European convention for the protection of vertebrate animals used for experimental and other scientific purposes. Male Wistar rats $($ MCT model $n=8 /$ control $n=5)$ and male Sprague Dawley rats (SuHx model $n=8 / \operatorname{control~} n=5$ ) (Charles River, The Netherlands) were housed in groups of 3-4 under controlled conditions (22 degrees, 12:12 h light/dark cycle). Food and water were available ad libitum.

\subsection{Study Design}

The rats were randomly divided in three groups: control (CON), SuHx and MCT, and the results were compared to both iPAH and hPAH. Control group consisted of a 50/50 mix of Wistar and Sprague Dawley rats. The SuHx protocol was followed as described previously [29]. Briefly, the Sprague Dawley animals were injected with SU5416 (25 mg/kg s.c.), Tocris Bioscience, \#3037, Bristol, United Kingdom, dissolved in carboxymethylcellulose (CMC)) and exposed to hypoxia (10\%) for four weeks followed by re-exposure to normoxia for 6 weeks. Wister rats received a single dose of monocrotaline $(60 \mathrm{mg} / \mathrm{kg}$ s.c.) to initiate the development of PAH. The CON group received a single shot of the solvent CMC (SuHx) or sterile saline (MCT). Experiments were terminated 4 weeks post-MCT injection or 6 weeks post hypoxia. The timing of the end-experiments was chosen to ensure the full development of PAH and end-stage pulmonary vascular remodeling $[29,30]$. The animals were killed via exsanguination and the organs were weighed and processed for analysis.

\subsection{Right Ventricle Pressure Measurements}

Prior to the termination of the experiment, open-chest right ventricle (RV) catheterization was performed under general anesthesia in all animals (3.0\% isoflurane, 1:1 $\mathrm{O}_{2} /$ air mix) as described previously elsewhere [31]. The catheter was inserted through the RV wall. The rats were intubated (Teflon tube, 16 gauge) and attached to a mechanical ventilator (Micro-Ventilator, UNO, Zevenaar, The Netherlands; ventilator settings: breathing frequency, 70 breaths per minute; pressures, $12 / 0 \mathrm{~cm}$ 
$\mathrm{H}_{2} \mathrm{O}$; inspiratory/expiratory ratio, 1:1). RV pressures were recorded using a microtip pressure-volume conductance catheter (Millar Instruments, Houston, TX, USA). Analyses were performed when a steady state was reached over an interval of at least $10 \mathrm{~s}$.

\subsection{Histology and Morphometry}

The lungs were weighed and the airways of the right middle lobe were filled with $0.5 \%$ low-melt agarose in saline under constant pressure of $25 \mathrm{mmHg}$ and stored in formalin (\#4169-30, Klinipath BV, Duiven, The Netherlands). The remaining lobes were stored in liquid nitrogen for future processing. The heart was perfused with tyrode solution, weighed, dissected, snap-frozen in liquid nitrogen and stored in $-80^{\circ} \mathrm{C}$. Transversally cut lung sections $(4 \mu \mathrm{m})$ were stained with Elastica van Gieson (EvG) for the analysis of vascular dimensions. The degree of vascular occlusion was expressed by the percentage of occluded vessels determined on a minimum of 30 vessels per animal per group [31].

\subsection{Western Blot}

RIPA lysis buffer (89900, Thermofisher scientific, Breda, The Netherlands) with protease inhibitors (PMSF, Thermofisher scientific/complete mini protease inhibitor cocktail, Sigma-Aldrich, Zwijndrecht, The Netherlands) were added to the lung tissue and homogenized with a tissue lyser (Qiagen, Venlo, The Netherlands). Protein concentration was quantified by protein assay kit (Thermo Scientific, Pierce Biotechnology, Rockford, IL, USA). The samples (10 $\mu \mathrm{g})$ were separated on a gradient gel (Bis-Tris $4-12 \%$ gel, Life technologies). XCell blot module was used for protein transfer from the gel to an ECL membrane (Hybond ECL Nitrocellulose Membrane, GE Healthcare). Primary antibody for BMPR2 (1:1000, MA5-15827, Thermo scientific, Breda, The Netherlands)/phospho-Smad 1/5/8 (\#12656, Cell Signaling, Leiden, The Netherlands)) diluted in phosphate buffered saline with bovine serum albumin (5\%) (PBS-A) was incubated overnight at $4{ }^{\circ} \mathrm{C}$. Appropriate secondary antibody (1:4000, Polyclonal rabbit anti-mouse, Z0259, DAKO) diluted in PBS-A was incubated for one hour. The blots were re-incubated with $\beta$-actin (1:50000, A3854, Sigma) or GAPDH diluted in PBS for one hour to correct for unequal loading. An internal control composed of a mix of protein supernatants from all groups was used to correct for inter-blot variation.

\subsection{Immunofluorescence Staining and Quantitative Analysis}

After deparaffinization and hydration, epitope retrieval was performed by immersing the slides in antigen unmasking solution (H3300, Vector Laboratories) for $20 \mathrm{~min}$. Blocking steps with 1\% bovine serum albumin were performed for $90 \mathrm{~min}$, before incubating the sections with primary antibodies BMPR2 (MA5-15827, Thermo scientific or 612292, BD Biosciences, 1:50) and phospho-Smad 1/5/8 (\#12656, Cell Signaling, 1:50) overnight at $4{ }^{\circ} \mathrm{C}$. For the negative controls, the primary antibody was omitted to account for the nonspecific binding of the secondary antibody. Labeling with appropriate secondary antibody conjugated to Cy5 followed for $90 \mathrm{~min}$. Additional overnight staining with pre-conjugated anti-actin $\alpha$-smooth-muscle-actin-Cy3 ( $\alpha$-SMA, C6198, Sigma), Von Willebrand Factor FITC (VWF, ab8822, Abcam) was performed before a 10 min incubation with 4'6-diamidino-2-phenylindole (DAPI, H-1200, Vector Labs) prior to sealing. Image acquisition was performed on a ZEISS Axiovert 200M Marianas inverted microscope. All the BMPR2 and psmad 1/5/8 images were acquired in a single session. Exposure time for the protein of interest was determined automatically by software (Slidebook 6, Intelligent imaging innovations) once and used for all subsequent slides. The negative control was used to determine and set a low signal threshold. Figures were assembled using an Adobe Illustrator (AI, version 23.03).

BMPR2 expression was determined per high power field (at 400X) and corrected for vessel area by assigning a region of interest (ROI) using FIJI software [32]. ROI was created by manually drawing the vessel circumference subtracted by vessel lumen (if applicable). The average intensity of the BMPR2 signal in ROI was used to quantify the expression per vessel. A minimum of 20 vessels per section were measured. Only the vessels in rats ranging from a 50-100 um diameter were included for analysis. 


\subsection{Statistical Analysis}

All the analyses were performed in a blinded fashion. All the data were verified for normal distribution. A $p$-value $<0.05$ was considered significant. All the data are presented as the mean \pm SEM. The parameters were analyzed by one-way ANOVA with Bonferroni post-hoc testing (GraphPad Prism for Windows 6, San Diego, CA, USA).

\section{Results}

\subsection{BMPR2 Levels Are not Decreased in Whole Lung Lysates of $i P A H$ and hPAH Patients}

We first analyzed the protein levels of BMPR2 and pSmad 1/5/8 in whole lung homogenates of samples derived from human PAH patients and controls subjects. Western blot analysis showed that BMPR2 was similar in iPAH and hPAH compared to control lung tissues (Figure 1A). In contrast, semi-quantitative analysis of the expression of BMPR2 in lung vessels by immunofluorescence (IF) revealed the reduced expression of the receptor in the vessels of both iPAH and hPAH patients, compared to the control, regardless of the mutational status $(p \leq 0.05)$ (Figure 1B,C).

\section{A}
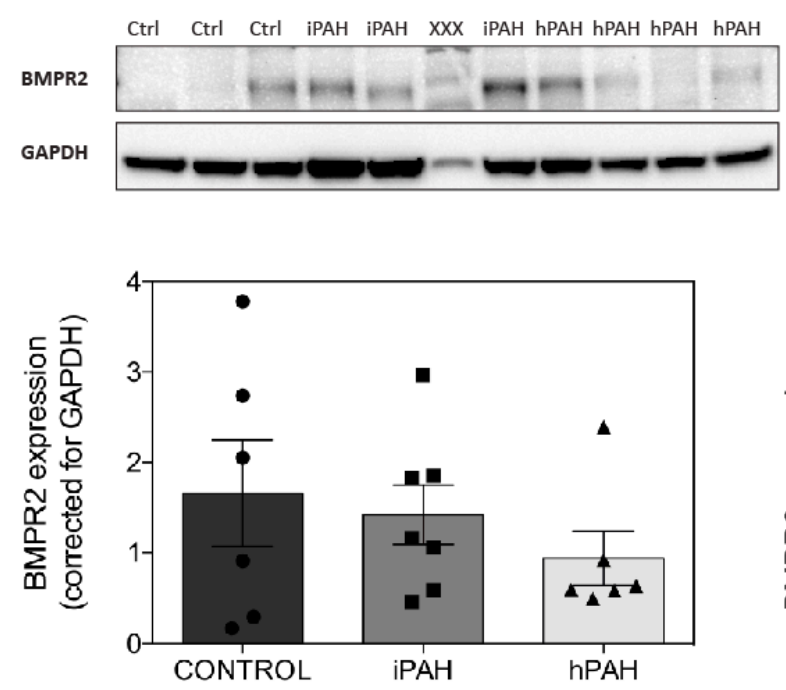

B

C

Control

iPAH
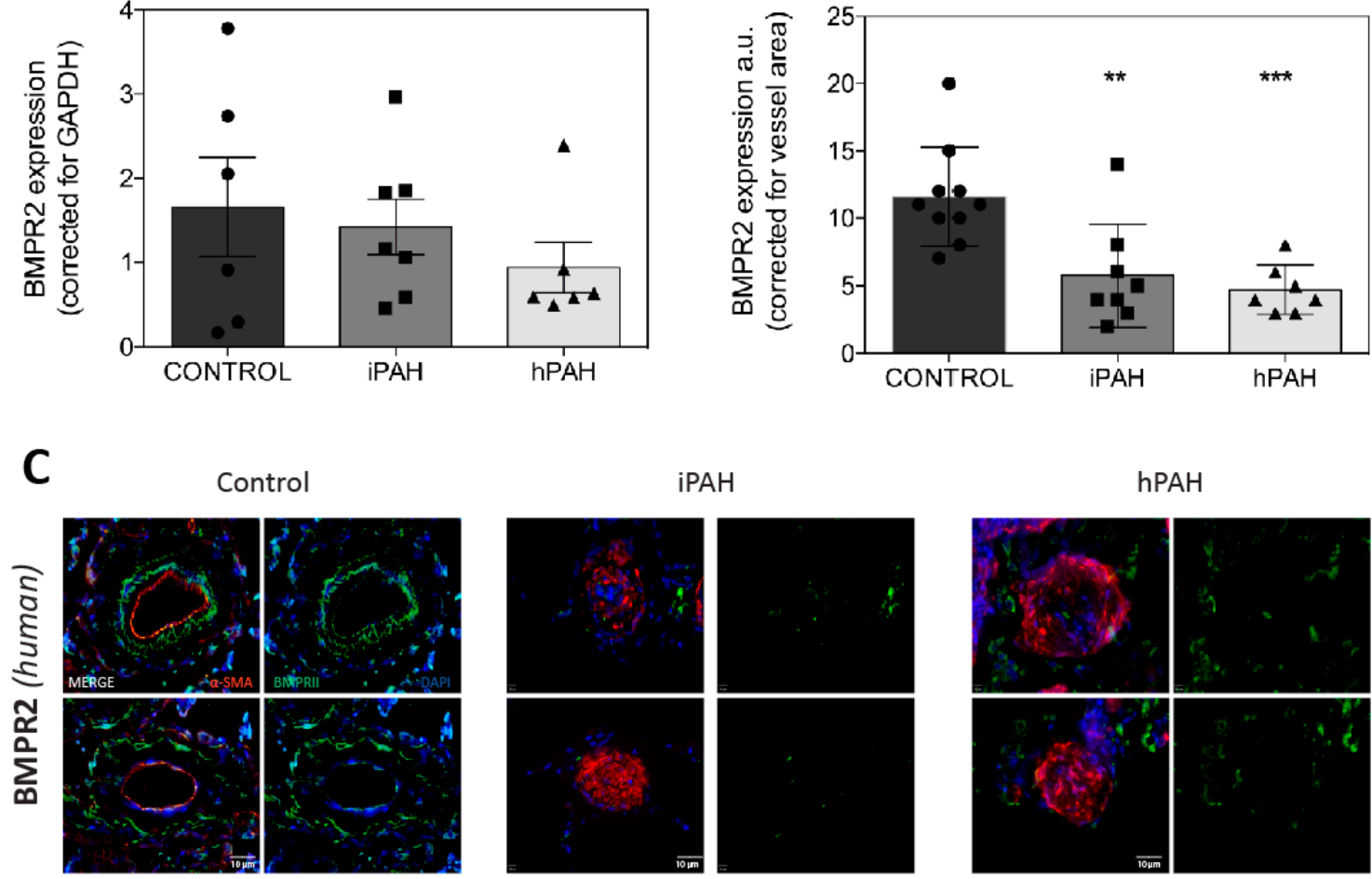

hPAH

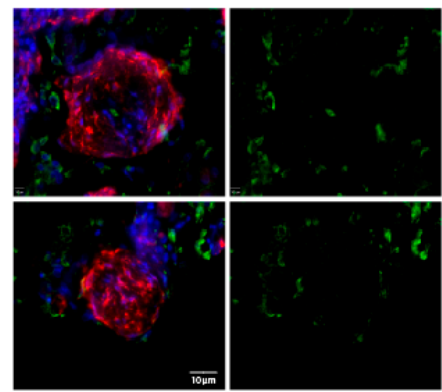

Figure 1. Western blot analysis of BMPR2 protein expression in the whole lung homogenates of idiopathic PAH (iPAH) and hereditary PAH (hPAH). (A): BMPR2 expression in the whole lung homogenates. $x x x=$ non-relevant sample. (B): BMPR2 expression corrected for the vessel area. (C): Typical examples of vessels are shown. Green = BMPR2; red = smooth-muscle-actin ( $\alpha$-SMA); blue = nuclei. ${ }^{* *}=p<0.01 /^{* * *}=p<0.001$. 


\subsection{Decreased Levels of $p$ Smad $1 / 5 / 8$ in the Lung Vasculature of iPAH and $h P A H$ Patients}

Since the BMP Smad1/5/8 are considered to reflect BMP signaling and downstream events, we determined the levels of pSmad1/5/8 in the cell lysates of primary pulmonary micro vascular endothelial cells, following stimulation with BMP9 by Western blot. Like in several cell types, the levels of pSmad1/5/8 are increased, following stimulation with BMP9 in human pulmonary micro vascular endothelial cells (Figure S1). Analyzing the levels of phosphorylated Smad 1/5/8 protein in the whole lung homogenates of the control, iPAH and hPAH groups showed no significant differences (Figure 2A). However, there was a clear reduction in the expression of vascular pSmad 1/5/8 when comparing both iPAH and hPAH to the control vessels $(p<0.05)$ (Figure 2B,C).

A

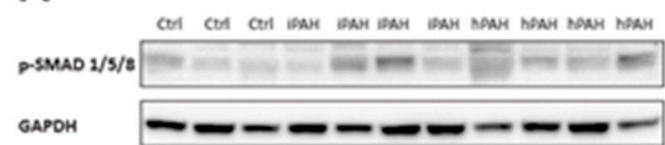

B
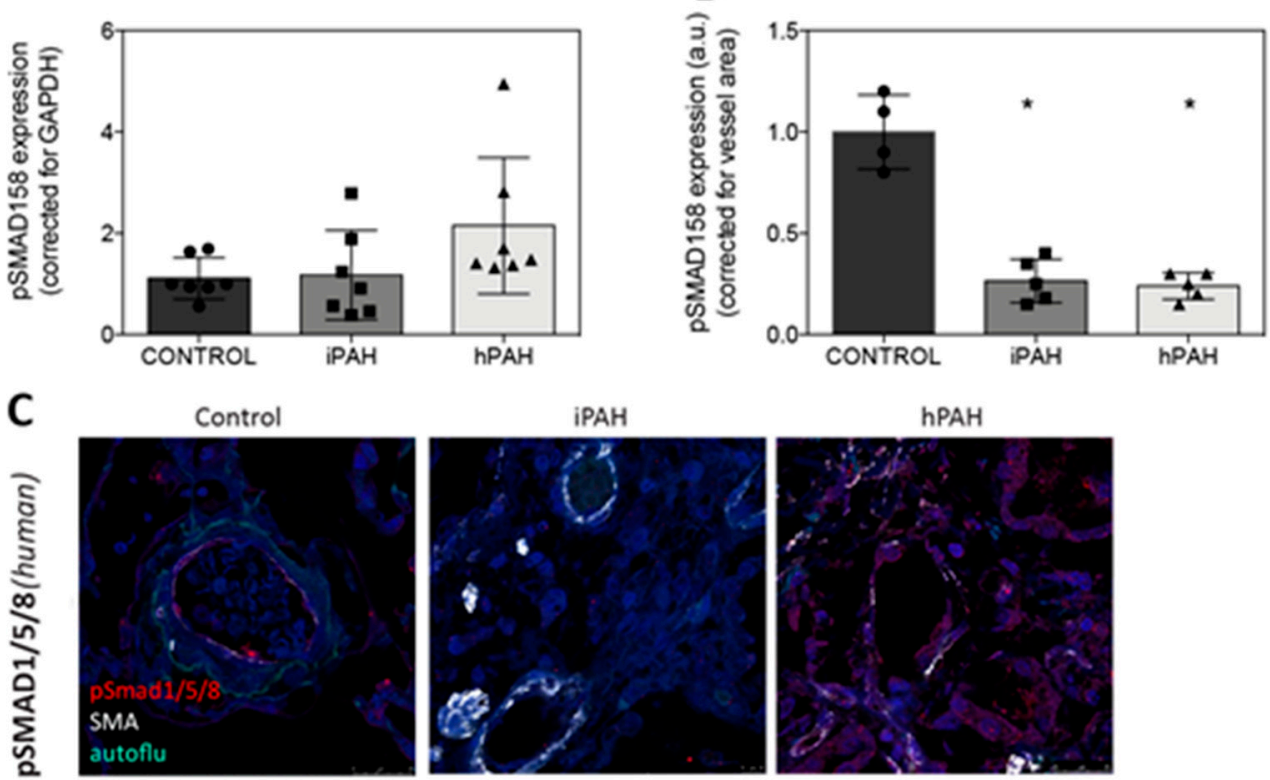

Figure 2. Analysis of Smad 1/5/8/ phosphorylation in the whole lung homogenates. (A): pSmad 1/5/8 in the whole lung homogenates. (B): pSmad 1/5/8 expression corrected for the vessel area. (C): Typical examples of the vessels are shown. Red $=$ pSmad 1/5/8; white $=$ smooth-muscle-actin; blue $=$ nuclei. autoflu=autofluroscence. Scale $=10 \mu \mathrm{m} .{ }^{*}=p<0.05$.

\subsection{Development of PAH in Animal Models}

Then, we sought to compare BMPR2-Smad signaling in human PAH with PAH induced in rats. Therefore, we first confirmed the development of PAH in our animal models by the increase in right ventricle systolic pressure (RVSP), the increased RV hypertrophy $(\mathrm{RV} / \mathrm{LV}+\mathrm{S})$ and the increased vascular remodeling (Figure 3). 
A

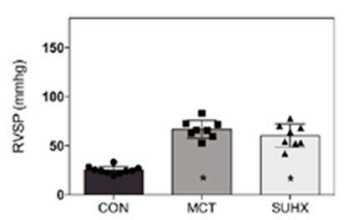

CONTROL

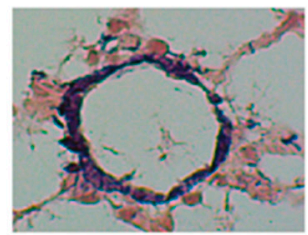

B

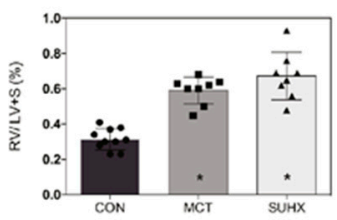

MCT

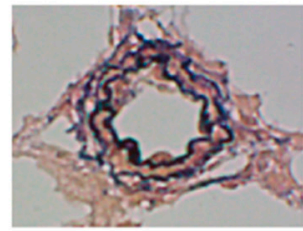

C

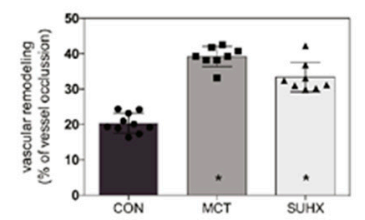

SUHX

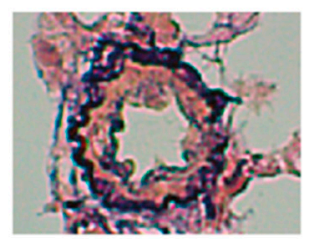

Figure 3. Characteristics of pulmonary arterial hypertension (PAH) animal models: Monocrotaline $(\mathrm{MCT})$ and Sugen hypoxia (SuHx) with (A): RVSP = right ventricle systolic pressure, (B): Fulton index $(\mathrm{RV} / \mathrm{LV}+\mathrm{S})$ and $(\mathrm{C})$ : vascular remodeling. Typical examples of vessel remodeling are shown below (Elastica van Gieson (EvG) staining, 400× magnification). ${ }^{*}=p<0.05$.

\subsection{BMPR2 Expression Is Increased in MCT and SuHx Lung Vasculature}

Whole lung BMPR2 protein expression level was reduced in MCT $(p<0.05)$ but did not change in the SuHx model when compared to the control (Figure 4A). Using IF quantification corrected for the vessel area, and we observed a notable increase in the expression of BMPR2 in both the MCT and SuHx lung vasculature (Figure 4B,E). The ratio of pSmad 1/5/8 vs. total Smad 1/5/8, indicating BMPR2 activation, was similar in whole lung homogenates of MCT rats and SuHx rats (Figure $4 \mathrm{C}$ ). However, the ratio of pSmad $1 / 5 / 8$ vs. $\beta$-actin is reduced in whole lung homogenates of MCT rats (data not shown) indicating that reduced levels of pSmad1/5/8 is due to the reduced total Smad levels and not due to the impaired receptor activation/signaling. IF analysis demonstrated the reduced expression of vascular pSmad 1/5/8 in both PAH models (Figure 4D-F). As we opted to use both Wistar and Sprague Dawley rats in our control group we tested for the statistical difference of whole lung lysate BMPR2 protein expression between both strains. No difference in the BMPR2 protein expression was observed in the separate control group analysis (data not shown). 

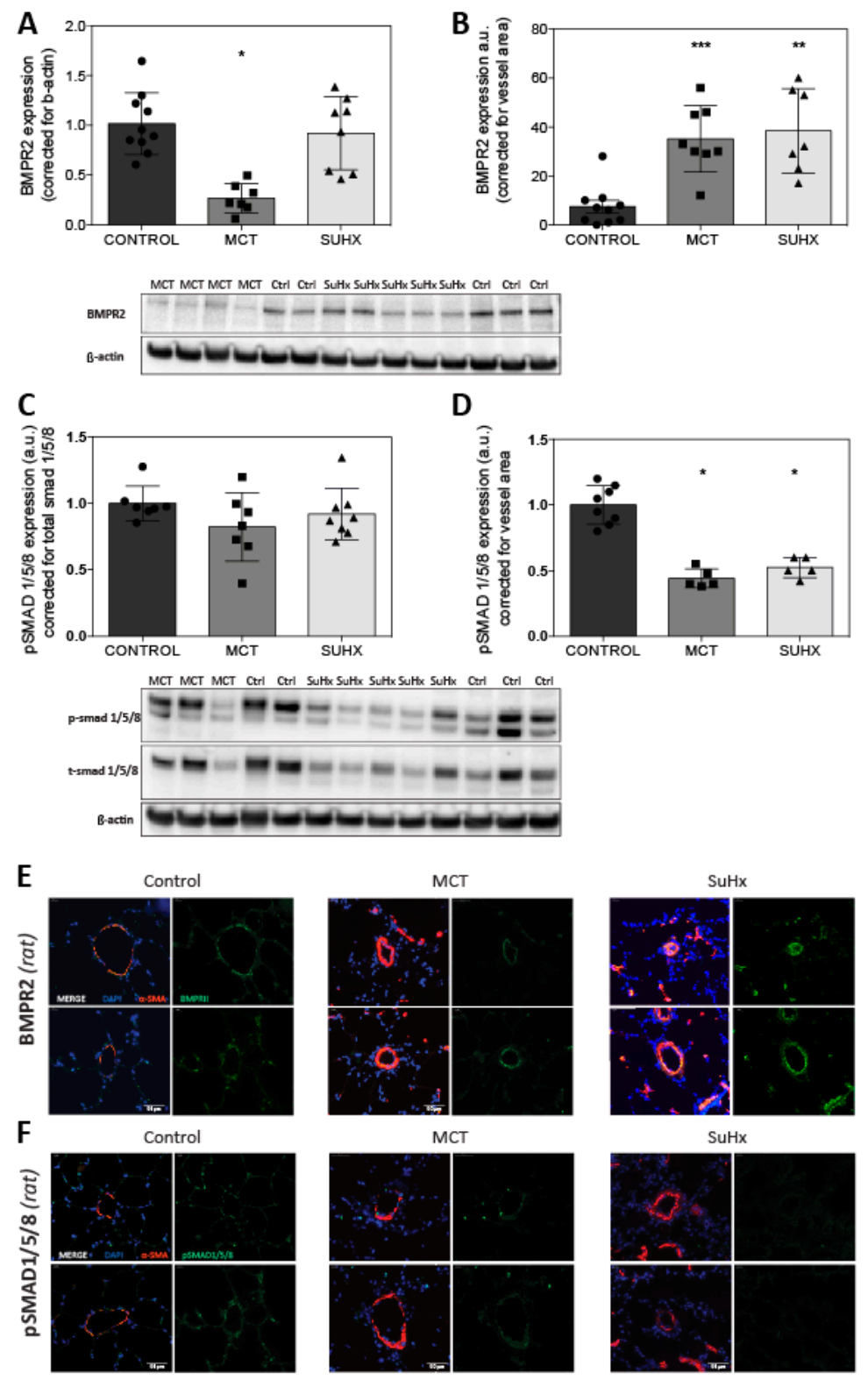

Figure 4. BMPR2 and pSmad 1/5/8 protein expression in the whole lung homogenates vs. immunofluorescence. (A-B): Analysis of the protein expression by Western blot; and (C-D): immunofluorescence. (E): Typical examples are shown. Green $=$ pSmad 1/5/8 or BMPR2; red = smooth-muscle-actin $(\alpha-S M A)$; blue $=$ nuclei. Scale bar $=50 \mu \mathrm{m} .{ }^{*}=p<0.05 /^{* *}=p<0.01 /^{* * *}=p<0.001$.

\section{Discussion}

This study describes the expression levels of BMPR2 and its downstream signaling component pSmad 1/5/8 in lung tissue and more specifically in the lung vasculature of PAH patients as well as in two established animal models of PAH. We confirmed the reduced protein expression of BMPR2 and its downstream signaling component, pSmad 1/5/8, in both hPAH and iPAH, but surprisingly, both the MCT and SuHx rats model for experimentally induced PAH showed an increased vascular expression of BMPR2 in the end stage disease. Downstream BMPR2 activity, as assessed by pSmad $1 / 5 / 8$ expression, was decreased in the lung vasculature of both PAH models, consistent with the patient situation. 


\subsection{Disturbed BMP Signaling in $P A H$ and $h P A H$}

The analysis of IF images showed a reduced vascular expression of BMPR2 in both iPAH and $\mathrm{hPAH}$, which is in concordance with a previous report of the reduced expression of BMPR2 in hPAH and iPAH determined by immunohistochemistry (IHC) [13]. While reduced BMPR2 expression in whole lung tissue samples from hPAH but not $\mathrm{PAH}$ was reported in a previous study using Western blot analysis [11], we did not observe a difference in the BMPR2 expression in hPAH/iPAH vs. controls in this study. An explanation for our findings perhaps lies in a different type of mutations that allows for the BMPR2 protein to be formed, but incorrectly expressed or unable to induce Smad $1 / 5 / 8$ phosphorylation. Another possible explanation is that we detected 115kDa protein of BMPR2 (predicted BMPR2 size is $115 \mathrm{kDa}$ ) whereas in the other study, we reported the $75 \mathrm{kDa}$ protein of BMPR2. Of note, we confirmed the specificity of the BMPR2 antibody by (1) knock-down studies using BMPR2 shRNAs in PAECs and PASMCs, (2) using a different BMPR2 antibody, and (3) using BMP9-stimulated PAEC lysates.

Previous studies showed that missense mutations in the ligand-binding domain by cysteine substitutions impair BMP signaling by mutant receptor mislocalization in the cytosol [33]. Furthermore, as autopsy material was used, it is possible that the cause and time of death may have inferred with BMPR2 signaling in non-vascular cells (e.g., epithelial or macrophage). The phosphorylation of Smad $1 / 5 / 8$ was decreased in the vasculature of both $\mathrm{PAH}$ and hPAH lungs suggesting that even in the absence of a BMPR2 mutation, BMP signaling is reduced. This observation is in line with another study showing a reduced number of Smad 1/5 positive cells by IHC in the vascular intimal and medial layer of iPAH and hPAH [34]. Richter and colleagues found the expression of phosphorylated Smad 1/5/8 in luminal endothelial cells in plexiform lesions, but pSmad1/5/8 was not present in the core endothelial cells. Unfortunately, the IHC data was not quantified [14].

\subsection{Reduced BMPR2 and pSmad 1/5/8 Expression in MCT and SuHx Animal Models of PAH}

Remarkably, using IF we observed the increased levels of BMPR2 in the lung vasculature of $\mathrm{MCT}$ and SuHx rats, while protein levels in the whole lung lysates were only reduced in the MCT model. Previously, Ramos et al [35]. reported reduced levels of BMPR2 protein by Western blot analysis using whole lung lysates 14 days after MCT injection. Others have described a brief initial increase in BMPR2 protein expression two days after MCT injection, with a subsequent decrease in BMPR2 protein levels after seven and twenty-one days [36-38] in whole lung homogenates by Western blot analysis. Impaired BMP signal transduction was confirmed in our study by reduced pSmad 1/5/8 expression in both MCT and SuHx. A recent study assessing the increase in BMPR2 signaling upon BMP9 stimulation observed the reduced levels of BMPR2 and pSmad 1/5/8 in the MCT model. For SuHx, only a reduction in the expression of $\mathrm{pSmad} 1 / 5 / 8$ was reported [39]. Other additional studies have also reported decreases in protein expression of $\mathrm{pSmad} 1 / 5 / 8[35,40]$. In contrast to these and our studies, one study reported augmented Smad1 signaling [35]. One difference in the methodological setup between this study and ours is the time post-MCT injection when the analysis was performed (14 vs. 28 days post-MCT). Since BMPR2 expression varies over the course of disease progression in the MCT model, the time difference is likely to exp-lain the difference in Smad1 signaling [37]. Our study opted for prolonged disease development before the analysis of the experimental PAH models, as at that time-point, it more closely resembles human end-stage disease. One explanation for the seemingly normal vascular BMPR2 expression in the SuHx model might be the role of vascular endothelial growth factor receptor 3 (VEGFR3). The blocking of VEGFR3 by sugen contributes to the vascular remodeling observed in the SuHx model, but recently VEGFR3 has also been linked to BMPR2 and PAH [41,42]. Hwangbo et al. propose a VEGFR3-BMPR2 interaction that is crucial for receptor endocytosis and the subsequent induction of the phosphorylation of Smads [43]. The inhibition of endocytosis by blocking VEGFR3 by sugen might therefore result in an increased BMPR2 vascular expression observed in PAH.

Analyzing vessels in more detail showed that in both MCT and SuHx animals, pSmad 1/5/8 is reduced while BMPR2 expression is increased. This increase in BMPR2 levels might be a feedback 
mechanism to restore endogenous BMP signaling and prevent disease progression, a process that has failed in the end-stage lung tissue of iPAH patients. It could also imply differences in BMPR2 and/or the type I receptor kinase activity [15], or the presence of inhibitors preventing BMPs binding to the receptor $[15,44]$. While our study was able to distinguish between the vascular vs. non-vascular expression of BMP signaling, it will be worthwhile to differentiate between the different vascular cell types. Even within the population of endothelial cells, the expression of phosphorylated Smad 1/5/8 was shown to differ upon location within a plexiform lesion [14]. In addition, the characterization of BMP signaling throughout the disease development might give more insight into the role of BMP signaling in the vascular remodeling in PAH. Perros et al. recently published their findings from a novel BMPR2 mutant rat model aimed to specifically model hPAH. These BMPR2 mutated rats spontaneously developed PAH between six and twelve months of age. Whole lung BMPR2 and pSmad 1/5/8 protein expression was lowered by fifty percent as measured by Western blot analysis [45]. Analyzing the lung vascular BMPR2 and pSmad 1/5/8 expression in this novel model would inform us if the expression is indeed similar to human disease.

\subsection{Interventions Aimed to Restore the TGF- $\beta / B M P$ Balance in Experimental PAH}

The inhibition of the lysosomal degradation of BMPR2 by chloroquine prevented the progression of PAH in the monocrotaline (MCT) model $[46,47]$. The restoration of downregulated BMPR2 signaling via the targeted gene delivery of BMPR2 revealed the therapeutic potential in the MCT model [36]. Sildenafil, a phosphodiesterase type 5 inhibitor currently registered for the treatment of $\mathrm{PAH}$, was demonstrated to restore MCT-induced $\mathrm{PH}$ in association with increased whole lung pSmad 1/5/8 expression [48]. Using laser dissection microscopy, Mcmurtry et al. showed the decreased BMPR2 mRNA expression in the MCT lung vasculature. Additionally, they showed a gradient in lung vascular BMPR2 mRNA expression with distal vessels having the highest expression levels compared to mid or proximal vessels. Gene therapy with BMPR2 distributed BMPR2 to resistance pulmonary arteries but did not ameliorate PAH in the MCT model [38]. Furthermore, in a study assessing the effect of a selective TGF- $\beta$ ligand trap, decreased levels of BMPR2 mRNA in SuHx and MCT lungs were unaffected by this treatment despite the effective reversal of $\mathrm{PH}$ [49]. Post or propter activation of BMPR2, FK506 (known as tacrolimus) reverse established PAH in the SuHx and MCT models [23,50]. In another study, the selective enhancement of BMPR2 signaling using BMP9 was shown to reverse disease in the MCT and SuHx models. In this study, whole lung pSmad 1/5 was reduced before treatment in both the MCT and SuHx model, while only in the MCT model was the lower whole lung BMPR2 protein expression was reported [39]. A multitude of other studies, investigating the compounds targeting BMPR2 signaling regulation, protein processing regulation, translational regulation, transcriptional regulation and genetic based therapies were performed or are currently ongoing [51-54].

The aim of this study was to give insights in the translational capability of two animal models commonly used to study new treatment modalities for PAH. Focusing on the BMPR2 signaling pathway as the main driver of the disease, both animal models only partly recapitulated the human situation. This study reconfirmed and added to the still limited body of evidence describing decreased vascular BMPR2 expression in PAH. Our contrasting findings of increased BMPR2 observed in the SuHx and MCT lung vasculature emphasizes the inadequacy of using whole lung lysates. We propose for future studies to not use whole lung lysates to determine BMPR2 levels, but more suitable techniques such as IF or IHC, which will allow to take into account the spatial localization of BMPR2 expression. Since the expression levels of BMPR2 are different in both MCT and SuHx models compared to hPAH or $\mathrm{iPAH}$, this should be taken into consideration when performing preclinical studies using a candidate compound to target BMPR2 or its downstream signaling component.

In conclusion, our findings confirm decreased BMPR2 receptor expression and downstream signaling activity in the lung vasculature of patients with idiopathic and hereditary PAH. At the same time, our study indicates that whole lung lysates are not representative of vascular BMPR2 and pSmad $1 / 5 / 8$ expression in the lung. Finally, despite an increased BMPR2 expression in the lung vasculature, 
PAH developed in the MCT and SuHx rat models and the downstream BMPR2 signaling activity resembled that of human PAH (Figure 5).

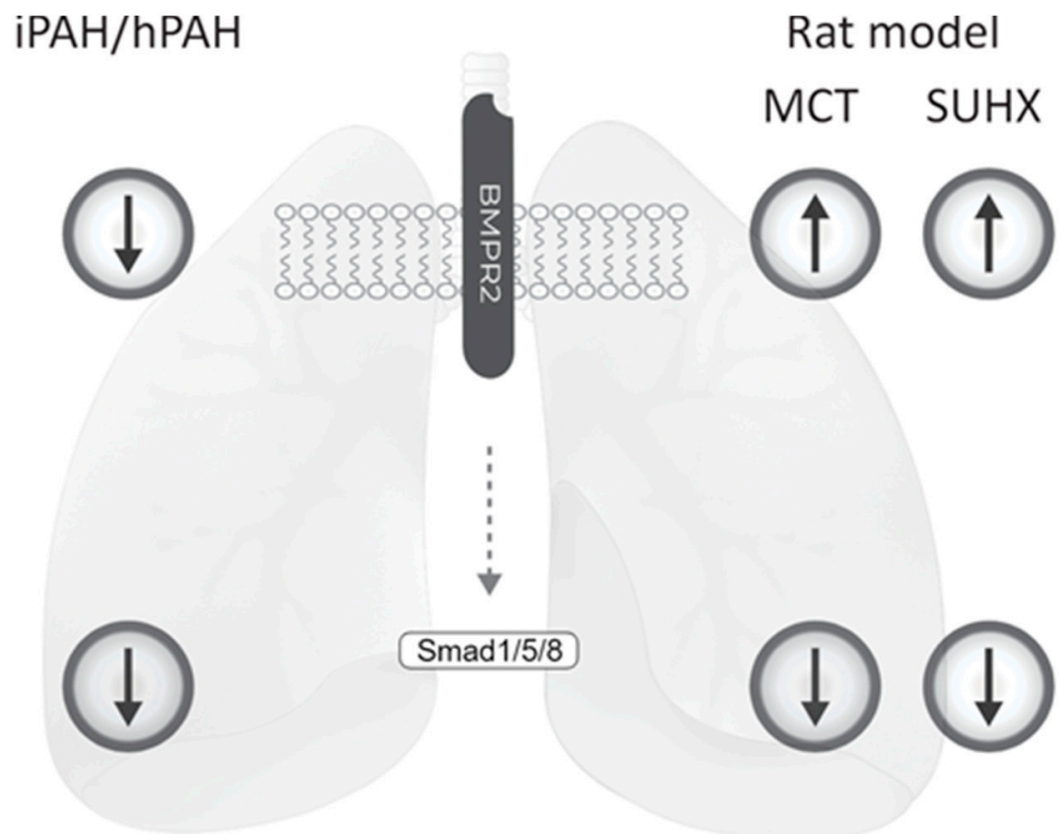

Figure 5. Schematic overviews summarizing the imaging results of this study. While BMPR2 protein expression is decreased in PAH along with decreased pSMAD 1/5/8 signaling, animal BMPR2 expression is increased in the lung vasculature.

Supplementary Materials: The following are available online at http://www.mdpi.com/2073-4409/9/6/1422/s1, Figure S1: BMP9 induces pSmad1/5/8 levels in microvascular endothelial cells.

Author Contributions: Conceptualization, C.H., K.K., H.J.B. and M.-J.G.; data curation, C.H., K.K., D.d.S.G.B., L.T. and K.C.W.; formal analysis, C.H., K.K., N.R. and C.G.; funding acquisition, A.V.N., H.J.B. and M.-J.G.; investigation, C.H., K.K. and I.S.; methodology, C.H., K.K., D.d.S.G.B., X.-Q.S., I.S. and K.C.W.; project administration, M.-J.G.; resources, D.d.S.G.B., X.-Q.S., C.G., L.T., O.T.-C. and M.-J.G.; software, N.R. and O.T.-C.; supervision, F.S.d.M., H.J.B. and M.-J.G.; validation, C.G. and L.T.; visualization, A.V.N., F.S.d.M., H.J.B. and M.-J.G.; writing-original draft, C.H. and K.K.; writing-review and editing, A.V.N., F.S.d.M., H.J.B. and M.-J.G. All authors have read and agreed to the published version of the manuscript.

Funding: This work was supported by the Dutch CardioVascular Alliance (DCVA): the Dutch Heart Foundation, Dutch Federation of University Medical Centers, The Netherlands Organization for Health Research and Development, and the Royal Netherlands Academy of Sciences Grant 2012-08 and 2018-2023 awarded to the Phaedra consortium (http://www.phaedraresearch.nl). We also acknowledge support for KK by the Dutch Lung Foundation (Longfonds) grant number-5.2.17.198J0 and by the Leiden University Foundation grant (W18378-2-32).

Acknowledgments: We thank Peter ten Dijke for the critical reading of the manuscript and providing valuable feedback. The authors also thank Marc Humbert, Elie Fadel, and their clinical and surgical teams for their expertise and support.

Conflicts of Interest: The authors declare no conflict of interest.

\section{References}

1. Simonneau, G.; Gatzoulis, M.A.; Adatia, I.; Celermajer, D.; Denton, C.; Ghofrani, A.; Gomez Sanchez, M.A.; Krishna Kumar, R.; Landzberg, M.; Machado, R.F.; et al. Updated Clinical Classification of Pulmonary Hypertension. J. Am. Coll. Cardiol. 2013, 62, D34-D41. [CrossRef] [PubMed]

2. Thomson, J.R.; Machado, R.D.; Pauciulo, M.W.; Morgan, N.V.; Humbert, M.; Elliott, G.C.; Ward, K.; Yacoub, M.; Mikhail, G.; Rogers, P.; et al. Sporadic primary pulmonary hypertension is associated with germline mutations of the gene encoding BMPR-II, a receptor member of the TGF- $\beta$ family. J. Med. Genet. 2000, 37, 741-745. [CrossRef] [PubMed] 
3. Lane, K.B.; Machado, R.D.; Pauciulo, M.W.; Thomson, J.R.; Phillips, J.A.; Loyd, J.E.; Nichols, W.C.; Trembath, R.C. Heterozygous germline mutations in $B M P R 2$, encoding a TGF- $\beta$ receptor, cause familial primary pulmonary hypertension. Nat. Genet. 2000, 26, 81-84. [CrossRef] [PubMed]

4. Evans, J.D.W.; Girerd, B.; Montani, D.; Wang, X.-J.; Galiè, N.; Austin, E.D.; Elliott, G.; Asano, K.; Grünig, E.; Yan, Y.; et al. BMPR2 mutations and survival in pulmonary arterial hypertension: An individual participant data meta-analysis. Lancet Respir. Med. 2016, 4, 129-137. [CrossRef]

5. Austin, E.D.; Ma, L.; LeDuc, C.; Rosenzweig, E.B.; Borczuk, A.; Phillips, J.A.; Palomero, T.; Sumazin, P.; Kim, H.R.; Talati, M.H.; et al. Whole Exome Sequencing to Identify a Novel Gene (Caveolin-1) Associated with Human Pulmonary Arterial HypertensionClinical Perspective. Circ. Cardiovasc. Genet. 2012, 5, 336-343. [CrossRef]

6. Wang, G.; Fan, R.; Ji, R.; Zou, W.; Penny, D.J.; Varghese, N.P.; Fan, Y. Novel homozygous BMP9 nonsense mutation causes pulmonary arterial hypertension: A case report. BMC Pulm. Med. 2016, 16, 17. [CrossRef]

7. Girerd, B.; Montani, D.; Coulet, F.; Sztrymf, B.; Yaici, A.; Jaïs, X.; Tregouet, D.; Reis, A.; Drouin-Garraud, V.; Fraisse, A.; et al. Clinical outcomes of pulmonary arterial hypertension in patients carrying an ACVRL1 (ALK1) mutation. Am. J. Respir. Crit. Care Med. 2010, 181, 851-861. [CrossRef]

8. Shintani, M.; Yagi, H.; Nakayama, T.; Saji, T.; Matsuoka, R. A new nonsense mutation of SMAD8 associated with pulmonary arterial hypertension. J. Med. Genet. 2009, 46, 331-337. [CrossRef]

9. Drake, K.M.; Dunmore, B.J.; McNelly, L.N.; Morrell, N.W.; Aldred, M.A. Correction of Nonsense BMPR2 and SMAD9 Mutations by Ataluren in Pulmonary Arterial Hypertension. Am. J. Respir. Cell Mol. Biol. 2013, 49, 403-409. [CrossRef]

10. Pousada, G.; Baloira, A.; Fontán, D.; Núñez, M.; Valverde, D. Mutational and clinical analysis of the ENG gene in patients with pulmonary arterial hypertension. BMC Genet. 2016, 17, 72. [CrossRef]

11. Dewachter, L.; Adnot, S.; Guignabert, C.; Tu, L.; Marcos, E.; Fadel, E.; Humbert, M.; Dartevelle, P.; Simonneau, G.; Naeije, R.; et al. Bone morphogenetic protein signalling in heritable versus idiopathic pulmonary hypertension. Eur. Respir. J. 2009, 34, 1100-1110. [CrossRef] [PubMed]

12. Lavoie, J.R.; Ormiston, M.L.; Perez-Iratxeta, C.; Courtman, D.W.; Jiang, B.; Ferrer, E.; Caruso, P.; Southwood, M.; Foster, W.S.; Morrell, N.W.; et al. Proteomic Analysis Implicates Translationally Controlled Tumor Protein as a Novel Mediator of Occlusive Vascular Remodeling in Pulmonary Arterial Hypertension. Circulation 2014, 129, 2125-2135. [CrossRef] [PubMed]

13. Atkinson, C. Primary Pulmonary Hypertension Is Associated with Reduced Pulmonary Vascular Expression of Type II Bone Morphogenetic Protein Receptor. Circulation 2002, 105, 1672-1678. [CrossRef] [PubMed]

14. Richter, A.; Yeager, M.E.; Zaiman, A.; Cool, C.D.; Voelkel, N.F.; Tuder, R.M. Impaired Transforming Growth Factor- $\beta$ Signaling in Idiopathic Pulmonary Arterial Hypertension. Am. J. Respir. Crit. Care Med. 2004, 170, 1340-1348. [CrossRef]

15. Morrell, N.W.; Bloch, D.B.; ten Dijke, P.; Goumans, M.-J.T.H.; Hata, A.; Smith, J.; Yu, P.B.; Bloch, K.D. Targeting BMP signalling in cardiovascular disease and anaemia. Nat. Rev. Cardiol. 2016, 13, 106-120. [CrossRef]

16. Nasim, M.T.; Ogo, T.; Chowdhury, H.M.; Zhao, L.; Chen, C.; Rhodes, C.; Trembath, R.C. BMPR-II deficiency elicits pro-proliferative and anti-apoptotic responses through the activation of TGF $\beta$-TAK1-MAPK pathways in PAH. Hum. Mol. Genet. 2012, 21, 2548-2558. [CrossRef]

17. Soon, E.; Crosby, A.; Southwood, M.; Yang, P.; Tajsic, T.; Toshner, M.; Appleby, S.; Shanahan, C.M.; Bloch, K.D.; Pepke-Zaba, J.; et al. BMPR-II Deficiency Promotes Pulmonary Hypertension via Increased Inflammatory Cytokine Production. Am. J. Respir. Crit. Care Med. 2015, 192, 859-872. [CrossRef]

18. Upton, P.D.; Morrell, N.W. The transforming growth factor- $\beta$-bone morphogenetic protein type signalling pathway in pulmonary vascular homeostasis and disease. Exp. Physiol. 2013, 98, 1262-1266. [CrossRef]

19. Dorfmüller, P.; Perros, F.; Balabanian, K.; Humbert, M. Inflammation in pulmonary arterial hypertension. Eur. Respir. J. 2003, 22, 358-363. [CrossRef]

20. Goumans, M.-J.; Valdimarsdottir, G.; Itoh, S.; Rosendahl, A.; Sideras, P.; ten Dijke, P. Balancing the activation state of the endothelium via two distinct TGF-beta type I receptors. EMBO J. 2002, 21, 1743-1753. [CrossRef]

21. Gore, B.; Izikki, M.; Mercier, O.; Dewachter, L.; Fadel, E.; Humbert, M.; Dartevelle, P.; Simonneau, G.; Naeije, R.; Lebrin, F.; et al. Key Role of the Endothelial TGF- $\beta /$ ALK1/Endoglin Signaling Pathway in Humans and Rodents Pulmonary Hypertension. PLoS ONE 2014, 9, e100310. [CrossRef] 
22. Davies, R.J.; Holmes, A.M.; Deighton, J.; Long, L.; Yang, X.; Barker, L.; Walker, C.; Budd, D.C.; Upton, P.D.; Morrell, N.W. BMP type II receptor deficiency confers resistance to growth inhibition by TGF- $\beta$ in pulmonary artery smooth muscle cells: Role of proinflammatory cytokines. Am. J. Physiol.-Lung Cell. Mol. Physiol. 2012, 302, L604-L615. [CrossRef] [PubMed]

23. Ramachandran, A.; Vizán, P.; Das, D.; Chakravarty, P.; Vogt, J.; Rogers, K.W.; Müller, P.; Hinck, A.P.; Sapkota, G.P.; Hill, C.S. TGF- $\beta$ uses a novel mode of receptor activation to phosphorylate SMAD1/5 and induce epithelial-to-mesenchymal transition. eLife 2018, 7, e31756. [CrossRef] [PubMed]

24. Spiekerkoetter, E.; Tian, X.; Cai, J.; Hopper, R.K.; Sudheendra, D.; Li, C.G.; El-Bizri, N.; Sawada, H.; Haghighat, R.; Chan, R.; et al. FK506 activates BMPR2, rescues endothelial dysfunction, and reverses pulmonary hypertension. J. Clin. Investig. 2013, 123, 3600-3613. [CrossRef] [PubMed]

25. Nickel, N.P.; Spiekerkoetter, E.; Gu, M.; Li, C.G.; Li, H.; Kaschwich, M.; Diebold, I.; Hennigs, J.K.; Kim, K.-Y.; Miyagawa, K.; et al. Elafin Reverses Pulmonary Hypertension via Caveolin-1-Dependent Bone Morphogenetic Protein Signaling. Am. J. Respir. Crit. Care Med. 2015, 191, 1273-1286. [CrossRef]

26. Kay, J.M.; Harris, P.; Heath, D. Pulmonary hypertension produced in rats by ingestion of Crotalaria spectabilis seeds. Thorax 1967, 22, 176-179. [CrossRef]

27. Taraseviciene-Stewart, L.; Kasahara, Y.; Alger, L.; Hirth, P.; Mahon, G.M.; Waltenberger, J.; Voelkel, N.F.; Tuder, R.M. Inhibition of the VEGF receptor 2 combined with chronic hypoxia causes cell death-dependent pulmonary endothelial cell proliferation and severe pulmonary hypertension. FASEB J. 2001, 15, 427-438. [CrossRef]

28. Overbeek, M.J.; Mouchaers, K.T.B.; Niessen, H.M.; Hadi, A.M.; Kupreishvili, K.; Boonstra, A.; Voskuyl, A.E.; Belien, J.A.M.; Smit, E.F.; Dijkmans, B.C.; et al. Characteristics of Interstitial Fibrosis and Inflammatory Cell Infiltration in Right Ventricles of Systemic Sclerosis-Associated Pulmonary Arterial Hypertension. Available online: https://www.hindawi.com/journals/ijr/2010/604615/abs/ (accessed on 20 April 2019).

29. De Raaf, M.A.; Schalij, I.; Gomez-Arroyo, J.; Rol, N.; Happé, C.; de Man, F.S.; Vonk-Noordegraaf, A.; Westerhof, N.; Voelkel, N.F.; Bogaard, H.J. SuHx rat model: Partly reversible pulmonary hypertension and progressive intima obstruction. Eur. Respir. J. 2014, 44, 160-168. [CrossRef]

30. Handoko, M.L.; de Man, F.S.; Happé, C.M.; Schalij, I.; Musters, R.J.P.; Westerhof, N.; Postmus, P.E.; Paulus, W.J.; van der Laarse, W.J.; Vonk-Noordegraaf, A. Opposite Effects of Training in Rats with Stable and Progressive Pulmonary Hypertension. Circulation 2009, 120, 42-49. [CrossRef]

31. Happé, C.M.; de Raaf, M.A.; Rol, N.; Schalij, I.; Vonk-Noordegraaf, A.; Westerhof, N.; Voelkel, N.F.; de Man, F.S.; Bogaard, H.J. Pneumonectomy combined with SU5416 induces severe pulmonary hypertension in rats. Am. J. Physiol. Lung Cell. Mol. Physiol. 2016, 310, L1088-L1097. [CrossRef]

32. Schindelin, J.; Arganda-Carreras, I.; Frise, E.; Kaynig, V.; Longair, M.; Pietzsch, T.; Preibisch, S.; Rueden, C.; Saalfeld, S.; Schmid, B.; et al. Fiji: An open-source platform for biological-image analysis. Nat. Methods 2012, 9, 676-682. [CrossRef] [PubMed]

33. Rudarakanchana, N.; Flanagan, J.A.; Chen, H.; Upton, P.D.; Machado, R.; Patel, D.; Trembath, R.C.; Morrell, N.W. Functional analysis of bone morphogenetic protein type II receptor mutations underlying primary pulmonary hypertension. Hum. Mol. Genet. 2002, 11, 1517-1525. [CrossRef] [PubMed]

34. Yang, X. Dysfunctional Smad Signaling Contributes to Abnormal Smooth Muscle Cell Proliferation in Familial Pulmonary Arterial Hypertension. Circ. Res. 2005, 96, 1053-1063. [CrossRef]

35. Ramos, M.F.; Lamé, M.W.; Segall, H.J.; Wilson, D.W. Smad Signaling in the Rat Model of Monocrotaline Pulmonary Hypertension. Toxicol. Pathol. 2008, 36, 311-320. [CrossRef]

36. Reynolds, A.M.; Holmes, M.D.; Danilov, S.M.; Reynolds, P.N. Targeted gene delivery of BMPR2 attenuates pulmonary hypertension. Eur. Respir. J. 2012, 39, 329-343. [CrossRef]

37. Long, L.; Crosby, A.; Yang, X.; Southwood, M.; Upton, P.D.; Kim, D.-K.; Morrell, N.W. Altered Bone Morphogenetic Protein and Transforming Growth Factor- Signaling in Rat Models of Pulmonary Hypertension: Potential for Activin Receptor-Like Kinase-5 Inhibition in Prevention and Progression of Disease. Circulation 2009, 119, 566-576. [CrossRef]

38. McMurtry, M.S.; Moudgil, R.; Hashimoto, K.; Bonnet, S.; Michelakis, E.D.; Archer, S.L. Overexpression of human bone morphogenetic protein receptor 2 does not ameliorate monocrotaline pulmonary arterial hypertension. Am. J. Physiol. Lung Cell. Mol. Physiol. 2007, 292, L872-L878. [CrossRef] [PubMed] 
39. Long, L.; Ormiston, M.L.; Yang, X.; Southwood, M.; Gräf, S.; Machado, R.D.; Mueller, M.; Kinzel, B.; Yung, L.M.; Wilkinson, J.M.; et al. Selective enhancement of endothelial BMPR-II with BMP9 reverses pulmonary arterial hypertension. Nat. Med. 2015, 21, 777-785. [CrossRef]

40. Harper, R.L.; Reynolds, A.M.; Bonder, C.S.; Reynolds, P.N. BMPR2 gene therapy for PAH acts via Smad and non-Smad signalling. Respirology 2016, 21, 727-733. [CrossRef]

41. Al-Husseini, A.; Kraskauskas, D.; Mezzaroma, E.; Nordio, A.; Farkas, D.; Drake, J.I.; Abbate, A.; Felty, Q.; Voelkel, N.F. Vascular endothelial growth factor receptor 3 signaling contributes to angioobliterative pulmonary hypertension. Pulm. Circ. 2015, 5, 101-116. [CrossRef]

42. Hwangbo, C.; Lee, H.-W.; Kang, H.; Ju, H.; Wiley, D.S.; Papangeli, I.; Han, J.; Kim, J.-D.; Dunworth, W.P.; $\mathrm{Hu}, \mathrm{X}$; e et al. Modulation of Endothelial Bone Morphogenetic Protein Receptor Type 2 Activity by Vascular Endothelial Growth Factor Receptor 3 in Pulmonary Arterial Hypertension. Circulation 2017, 135, 2288-2298. [CrossRef] [PubMed]

43. Lee, H.-W.; Jin, S.-W. VEGFR3 as a novel modulator for PAH. Oncotarget 2017, 8, 84610-84611. [CrossRef] [PubMed]

44. Goumans, M.-J.; Zwijsen, A.; ten Dijke, P.; Bailly, S. Bone Morphogenetic Proteins in Vascular Homeostasis and Disease. Cold Spring Harb. Perspect. Biol. 2018, 10, a031989. [CrossRef] [PubMed]

45. Hautefort, A.; Mendes-Ferreira, P.; Sabourin, J.; Manaud, G.; Bertero, T.; Rucker-Martin, C.; Riou, M.; Adão, R.; Manoury, B.; Lambert, M.; et al. Bmpr2 Mutant Rats Develop Pulmonary and Cardiac Characteristics of Pulmonary Arterial Hypertension. Circulation 2019, 139, 932-948. [CrossRef] [PubMed]

46. Long, L.; Yang, X.; Southwood, M.; Lu, J.; Marciniak, S.J.; Dunmore, B.J.; Morrell, N.W. Chloroquine Prevents Progression of Experimental Pulmonary Hypertension via Inhibition of Autophagy and Lysosomal Bmpr-II Degradation. Circ. Res. 2013, 112, 1159-1170. [CrossRef]

47. Dunmore, B.J.; Drake, K.M.; Upton, P.D.; Toshner, M.R.; Aldred, M.A.; Morrell, N.W. The lysosomal inhibitor, chloroquine, increases cell surface BMPR-II levels and restores BMP9 signalling in endothelial cells harbouring BMPR-II mutations. Hum. Mol. Genet. 2013, 22, 3667-3679. [CrossRef]

48. Yang, J.; Li, X.; Al-Lamki, R.S.; Wu, C.; Weiss, A.; Berk, J.; Schermuly, R.T.; Morrell, N.W. Sildenafil Potentiates Bone Morphogenetic Protein Signaling in Pulmonary Arterial Smooth Muscle Cells and in Experimental Pulmonary Hypertension. Arterioscler. Thromb. Vasc. Biol. 2013, 33, 34-42. [CrossRef]

49. Yung, L.-M.; Nikolic, I.; Paskin-Flerlage, S.D.; Pearsall, R.S.; Kumar, R.; Yu, P.B. A Selective TGF $\beta$ Ligand Trap Attenuates Pulmonary Hypertension. Am. J. Respir. Crit. Care Med. 2016, 194, 1140-1151. [CrossRef]

50. Spiekerkoetter, E.; Sung, Y.K.; Sudheendra, D.; Scott, V.; Del Rosario, P.; Bill, M.; Haddad, F.; Long-Boyle, J.; Hedlin, H.; Zamanian, R.T. Randomised placebo-controlled safety and tolerability trial of FK506 (tacrolimus) for pulmonary arterial hypertension. Eur. Respir. J. 2017, 50, 1602449. [CrossRef]

51. Orriols, M.; Gomez-Puerto, M.C.; ten Dijke, P. BMP type II receptor as a therapeutic target in pulmonary arterial hypertension. Cell. Mol. Life Sci. 2017, 74, 2979-2995. [CrossRef]

52. Kurakula, K.; Sun, X.-Q.; Happé, C.; da Bos, D.S.G.; Szulcek, R.; Schalij, I.; Wiesmeijer, K.C.; Lodder, K.; Tu, L.; Guignabert, C.; et al. Prevention of Progression of Pulmonary Hypertension by the Nur77 Agonist 6-mercaptopurine: Role of BMP Signalling. Eur. Respir. J. 2019, 54, 1802400. [CrossRef] [PubMed]

53. Botros, L.; Szulcek, R.; Jansen, S.M.; Kurakula, K.; Goumans, M.T.; van Kuilenburg, A.B.P.; Vonk Noordegraaf, A.; de Man, F.S.; Aman, J.; Bogaard, H.J. The Effects of Mercaptopurine on Pulmonary Vascular Resistance and BMPR2 Expression in Pulmonary Arterial Hypertension. Am. J. Respir. Crit. Care Med. 2020. [CrossRef] [PubMed]

54. Van der Feen, D.E.; Kurakula, K.; Tremblay, E.; Boucherat, O.; Bossers, G.P.; Szulcek, R.; Bourgeois, A.; Lampron, M.-C.; Habbout, K.; Martineau, S.; et al. Multicenter Preclinical Validation of BET Inhibition for the Treatment of Pulmonary Arterial Hypertension. Am. J. Respir. Crit. Care Med. 2019, 200, 910-920. [CrossRef] [PubMed]

(C) 2020 by the authors. Licensee MDPI, Basel, Switzerland. This article is an open access article distributed under the terms and conditions of the Creative Commons Attribution (CC BY) license (http://creativecommons.org/licenses/by/4.0/). 